\title{
UPAYA MENINGKATKAN AKTIVITAS BELAJAR SISWA MELALUI MODEL PEMBELAJARAN COME'S TO PAPA PADA MATA PELAJARAN PKN DI KELAS XI.IPA.1 SMAN 1 KEC. LAREH SAGO HALABAN
}

\author{
RIZA DESRIANDI \\ SMAN 1 Kec. Lareh Sago Halaban, \\ reza_desriandi@yahoo.com
}

\begin{abstract}
Abstrak
Penelitian ini bertujuan untuk mendeskripsikan apakah dengan menggunakan model pembelajaran Come's to Papa (Cooperation Management and Part to Part) dalam pembelajaran PKN dapat meningkatkan aktivitas siswa dalam dalam belajar pada kelas XI.IPA.1 SMAN 1 Kec. Lareh Sago Halaban. Jenis penelitian yang dilakukan adalah penelitian tindakan kelas. Subjek penelitian ini siswa kelas XI.IPA.1 SMAN 1 Kec. Lareh Sago Halaban yang diambil secara purposive sampling. Data dikumpulkan melalui lembar observasi, dan dokumentasi.

Hasil penelitian menyimpulkan bahwa penggunaan model pembelajaran Come's to Papa (Cooperation Management and Part to Part) dapat meningkatkan aktivitas siswa dalam belajar PKn di kelas XI.IPA.1 SMAN $1 \mathrm{Kec}$. Lareh Sago Halaban. Hal ini terbukti dengan menggunakan model pembelajaran Come's to Papa (Cooperation Management and Part to Part) ini siswa sangat aktif dalam bertanya, mendengarkan diskusi, memberi tanggapan dan membuat laporan hasil kegiatan belajar. Hal ini dapat dilihat dari peningkatan persentase aktivitas belajar dari $64.55 \%$ disiklus I sampai $93.75 \%$ disikus ke II. Penggunaan model pembelajaran Come's to Papa (Cooperation Management and Part to Part) dapat memupuk keberanian siswa mengemukakan pendapat dan menumbuhkan sikap saling menghargai pendapat temannya sehingga dapat meningkatkan kekompakan dalam kelompok tersebut.
\end{abstract}

Dengan demikian berarti penggunaan model pembelajaran Come's to Papa (Cooperation Management and Part to Part) tersebut sangat berhasil di terapkan pada pembelajaran PKn dan mampu memotivasi siswa dalam proses pembelajaran di kelas XI.IPA.1 SMAN 1 Kec. Lareh Sago Halaban.

\section{KATA KUNCI : Aktivitas Belajar dan Model Pembelajaran Come's to Papa (Cooperation Management and Part to Part)}

\section{PENDAHULUAN}

Pendidikan merupakan modal yang sangat penting dalam proses pembangunan. Melalui dunia pendidikan kualitas yang dimiliki oleh seseorang tentunya akan lebih meningkat tidak hanya dari segi intelektual saja tetapi juga melatih emosional dan spiritual. Secara tidak langsung seseorang yang memiliki pendidikan yang tinggi dengan sendirinya akan mengangkat derajat orang tersebut di dalam lapisan masyarakat. Begitu pentingnya dunia pendidikan ini di berbagai kalangan masyarakat luas, khususnya Indonesia. Indonesia adalah negara yang berhasil 
merdeka karena salah satu faktornya yakni pendidikan. Pendidikan mampu membawa bangsa ini lepas dari belenggu penjajahan yang bertahan ratusan tahun lamanya. Pendidikan di Indonesia memang mengalami situasi yang terus berkembang. Hal ini dapat kita lihat melalui perkembangan kurikulum yang berlaku di Indonesia sejak awal hingga kurikulum tigabelas (kurtilas) revisi saat ini.

Pada dasarnya pengertian pendidikan (UU SISDIKNAS No.20 tahun 2003) adalah usaha sadar dan terencana untuk mewujudkan suasana belajar dan proses pembelajaran agar peserta didik secara aktif mengembangkan potensi dirinya untuk memiliki kekuatan spiritual keagamaan, pengendalian diri, kepribadian, kecerdasan, akhlak mulia, serta keterampilan yang diperlukan dirinya dan masyarakat. Disamping itu tujuan dari pendidikan itu sendiri adalah menciptakan seseorang yang berkualitas dan berkarakter sehingga memiliki pandangan yang luas kedepan untuk mencapai suatu cita- cita yang di harapkan dan mampu beradaptasi secara cepat dan tepat di dalam berbagai lingkungan sehingga dapat berguna bagi bangsa dan negara.

Salah satu ilmu yang membahas tentang keadaan bangsa dan negara itu sendiri adalah ilmu pendidikan kewarganegaraan (PKn). Melalui ilmu PKn kita bisa mengenal serta mengetahui bagaimana keadaan bangsa dan Negara kita sendiri, bagaimana bentuk pemerintahan yang ada di dalam Negara kita, serta hukum dan norma-norma yang berlaku di dalam pemerintahan Negara tersebut.

Tujuan dari mata pelajaran PKn itu sendiri adalah untuk membentuk pola dan prilaku atau etika yang baik agar dapat menjadi warga Negara yang berdaulat dan dapat berguna untuk kemajuan bangsa dan Negara. Disamping itu pembelajaran kewarganegaraan ini akan mengarahkan peserta didik agar memiliki jiwa nasionalisme yang kuat dan cinta akan tanah air atau bumi pertiwi. Jadi dapat dikatakan bahwa aspek kajian dalam PKn sangat berguna sekali untuk dipelajari dan dibahas dalam mata pelajaran di sekolah karena pendidikan kewarganegaraan tersebut sangat luas cangkupannya.

Dengan keadaan yang demikian tentunya pembelajaran PKn tersebut perlu dikaji dan digali lagi secara mendalam. Berbagai upaya telah dilakukan untuk meningkatkan akivitas peserta didik dalam mempelajari mata pelajaran PKn di jenjang pendidikan. Diantaranya dengan diterapkan nya model-model belajar yang menantang dan menyenangkan. Salah satunya adalah dengan adanya model Kooperatif Tipe Numbered Heads Together (NHT). Didalam model ini, siswa dituntut lebih aktif melalui pembelajaran kelompok dan diskusi serta berfikir bersama-sama dalam menyimpulkan materi pelajaran, agar siswa lebih mudah mengerti tentang materi pelajaran yang dibahas. Sehingga dengan keadaan yang demikian mata pelajaran PKn dapat membuat siswa aktif dan senang dalam proses pembelajaran.

Namun kenyataan yang terjadi adalah rendahnya aktivitas belajar siswa dalam pembelajaran PKn. Salah satu penyebabnya adalah penerapan metode belajar yang digunakan sangat membosankan dan tidak menyenangkan bagi siswa. Seningga siswa kurang memiliki aktivitas dalam proses pembelajaran diantaranya siswa kurang bertanya, kurang dalam menjawab pertanyaan, bahkan siswa kurang dalam menanggapi pelajaran. Disamping itu rendahnya kemampuan siswa dalam mesrespon dan bereaksi dalam kegiatan yang dilakukan pada proses belajar mengajar. materi pelajaran akan membantu pencapaian tujuan pembelajaran. 
Berdasarkan observasi yang telah dilakukan di SMAN 1 Kec. Lareh Sago Halaban banyak permasalahan yang dihadapi oleh siswa saat melakukan proses pembelajaran, terlihat bahwa aktivitas siswa dalam bertanya $15 \%$, menjawab $20 \%$, memberikan tanggapan 5\%, memberi saran 5\%, menyimpulkan pelajaran 5\%, masih memberikan saran 10\%, mengerjakan tugas $40 \%$, mencatat dan menjawab pertanyaan yang diajukan guru $45 \%$, dan kurang bisa bekerjasama dengan siswa lain serta kurang bertanggung jawab terhadap tugas yang diberikan.

Menyikapi permasalahan tersebut penulis sangat tertarik untuk mengadakan penelitian berkenaan dengan salah satu Pendekatan pembelajaran Come's to Papa (Cooperation Management And Part To Part) pada mata pelajaran PKn yang bertujuan untuk meningkatkan aktivitas siswa, dalam sebuah judul "Upaya Meningkatkan Aktivitas Belajar Siswa Melalui Model Pembelajaran Come's to Papa pada Mata Pelajaran PKn di Kelas XI.IPA.1 SMAN 1 Kec. Lareh Sago Halaban"

\section{METODE PENELITIAN}

Jenis penelitian ini adalah penelitian tindakan kelas (Classroom Action Research) adalah penelitian rekleftif oleh prilaku tindakan yang dilakukan oleh guru sendiri untuk memperbaiki proses pembelajaran yang menjadi tanggung jawabnya. Penelitian dilaksanakan di SMAN 1 Kec. Lareh Sago Halaban dalam Pembelajaran PKn (Pendidikan Pancasila Kewarganegaraan) Siswa Kelas XI.IPA.1 pada semester 1 Tahun Pelajaran 2018/2019. Subjek dalam penelitian ini adalah siswa kelas XI.IPA.1 SMAN 1 Kec. Lareh Sago Halaban yang berjumlah 32 siswa dengan komposisi siswa pada tabel 3.1 berikut :

\begin{tabular}{|l|l|l|}
\hline Jumlah siswa & Komposisi & Komposisi siswa \\
\hline 36 & 20 & perempuan \\
\hline & 16 & Laki-laki \\
\hline
\end{tabular}

Teknik yang digunakan adalah data tentang aktivitas belajar siswa setiap pertemuan didiskusikan dengan observer, kemudian diinterprestasikan untuk menentukan apakah aktivitas siswa kurang, cukup dan baik. Persentase aktivitas siswa ditentukan dengan rumus :

$$
\mathrm{P}=\frac{f}{n} \times 100 \%
$$

Keterangan :

$\mathrm{P}$ : persentase aktivitas siswa disetiap pertemuan

$f$ : frekuensi siswa yang aktif

$n$ : jumlah keseluruhan siswa yang diteliti

Standar penilaian yang digunakan untuk memberikan kesimpulan tersebut berupa \% menurut Arikunto (1989) dalam Butar (2003: 20):

$80 \% \leq$ Efektifitas $\leq 100 \%$ = Sangat tinggi

$61 \% \leq$ Efektifitas $\leq 79 \%=$ Tinggi 
$21 \% \leq$ Efektifitas $\leq 40 \%=$ Rendah

$0 \% \leq$ Efektifitas $\leq 20 \%=$ Sangat rendah

\section{HASIL PENELITIAN}

\section{SIKLUS 1}

Pada siklus I, penelitian dilaksanakan sebanyak dua kali pertemuan. Alokasi waktu untuk setiap pertemuan yaitu 2 x 45 menit. Materi yang disampaikan pada siklus I adalah menganalisis, mendeskripsikan. Pertemuan pada siklus pertama adalah 8 Agustus dan 15 Agustus 2018. Fokus penelitian ini adalah peningkatan aktivitas belajar siswa melalui model pembelajaran Come's to Papa (Cooperation Management and Part to Part).

Sesuai dengan perencanaan yang telah disepakati bersama, peneliti bertindak sebagai pengajar sedangkan teman sejawat bertindak sebagai pengamat atau observer. Sebelum memasuki materi baru peneliti menanyakan kepada siswa bagaimana materi sebelumnya, sesudah itu peneliti memberikan pengarahan kepada siswa bagaimana cara belajar kedepannya. Peneliti mengharapkan siswa bisa aktif dalam pembelajaran.

Pengamatan pada siklus pertama terdiri dari dua kali pertemuan. Materi yang diajarkan pada siklus pertama, dari hasil pengamatan selama pembelajaran pada siklus pertama diperoleh data tentang aktivitas belajar siswa.

Aktivitas siswa yang diamati meliputi aktivitas mengacungkan tangan saat bertanya dan saat guru memberi pertanyaan, aktivitas mendengarkan waktu guru menerangkan dan waktu mendengarkan diskusi, aktivitas memberikan pendapat/tanggapan ketika diberi kesempatan mengeluarkan pendapat, aktivitas memberikan laporan/menulis. Data yang diperoleh dicatat dan dipresentasekan. Data mengenai aktivitas belajar siswa selama proses pembelajaran pada siklus pertama dapat dilihat pada tabel 4.12 berikut ini:

Tabel 4.5 Rekapitulasi Frekuensi Aktivitas Belajar Siswa dari pertemuan I dan Pertemuan II

\begin{tabular}{|c|c|c|c|c|c|c|c|}
\hline \multirow{4}{*}{ No } & \multirow{4}{*}{ Aktivitas } & \multicolumn{6}{|c|}{ SIKLUS I } \\
\hline & & \multicolumn{2}{|c|}{$\begin{array}{c}\text { Pertemuan } \\
1\end{array}$} & \multicolumn{2}{|c|}{$\begin{array}{c}\text { Pertemuan } \\
2\end{array}$} & \multirow{2}{*}{\multicolumn{2}{|c|}{$\begin{array}{c}\text { Peningkatan } \\
\text { Pertemuan } 1 \text { ke } \\
2\end{array}$}} \\
\hline & & \multirow[t]{2}{*}{$\mathrm{F}$} & \multirow[t]{2}{*}{$\%$} & \multirow[t]{2}{*}{$\mathrm{F}$} & \multirow[t]{2}{*}{$\%$} & & \\
\hline & & & & & & $\mathrm{F}$ & $\%$ \\
\hline 1 & Bertanya & 14 & 38.88 & 23 & 63.80 & 9 & 25 \\
\hline 2 & $\begin{array}{l}\text { Mendengarkan } \\
\text { diskusi }\end{array}$ & 20 & 55.55 & 30 & 83.33 & 10 & 27.77 \\
\hline 3 & $\begin{array}{l}\text { Memberi } \\
\text { tanggapan }\end{array}$ & 10 & 27.77 & 15 & 41.66 & 5 & 13.88 \\
\hline 4 & $\begin{array}{l}\text { Membuat } \\
\text { laporan/ dan }\end{array}$ & 22 & 61.11 & 25 & 69.44 & 3 & 8.33 \\
\hline
\end{tabular}




\begin{tabular}{|c|l|l|l|l|l|l|}
\hline menulis & & & & & & \\
\hline Rata-rata & & 45.82 & & 64.55 & 6.75 & 18.75 \\
\hline
\end{tabular}

Sumber: pengolahan data primer, 2018

Dari tabel diatas terlihat adanya peningkatan aktivitas siswa dari pertemuan satu ke pertemuan kedua. Peningkatan aktivitas paling tinggi adalah mendengarkan diskusi rata-ratanya $27.77 \%$. Sedangkan aktivitas terendah yaitu membuat laporan/menulis rata-ratanya $8.33 \%$. gambar data pada keseluruhan pada silus I dapat dilihat pada grafik dibawah ini:

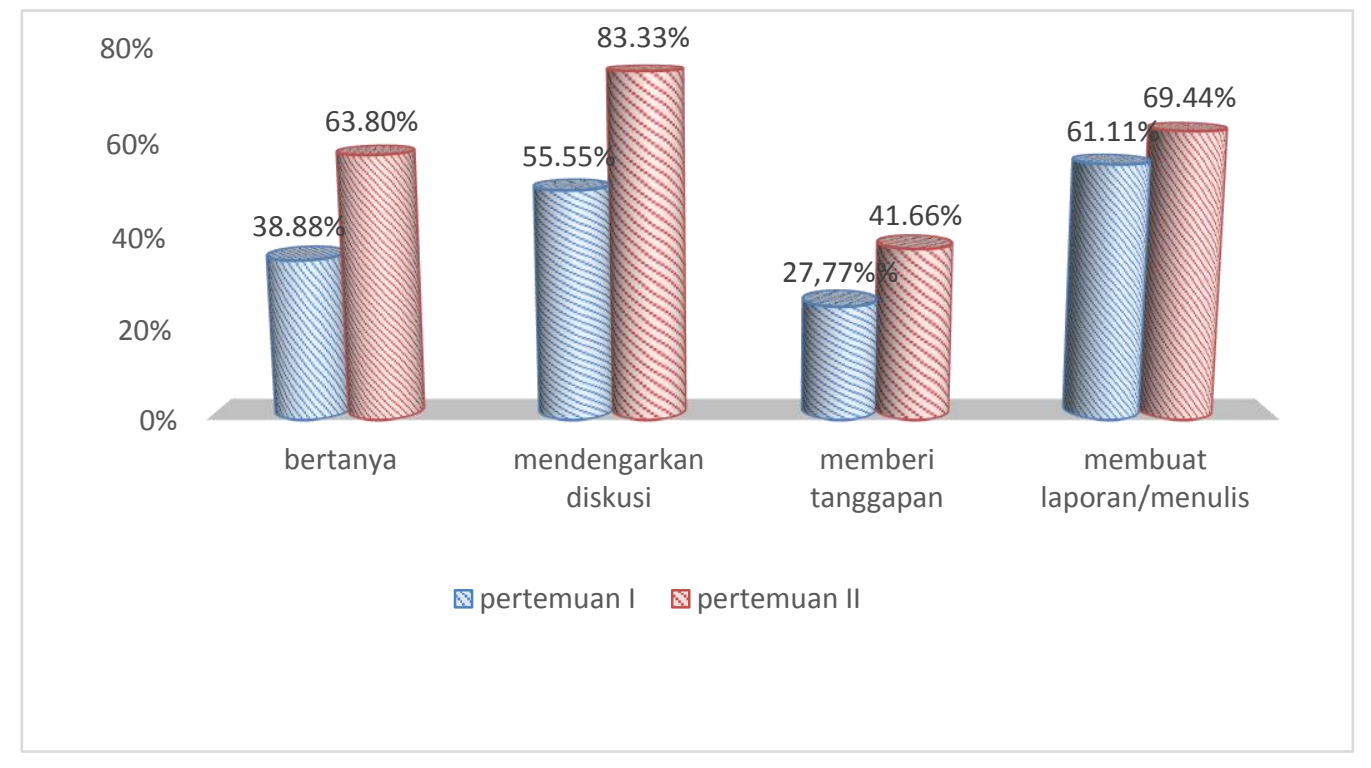

Gambar 4.1 grafik siklus 1

\section{SIKLUS 2}

Kegiatan Penelitian pada siklus kedua merupakan lanjutan dari siklus pertama, namun ada beberapa hal yang perlu diperbaiki, terutama yang berkaitan dengan peningkatan aktivitas belajar siswa. Pelaksanaan tindakan pada siklus kedua terdiri dari dua pertemuan.

Pada siklus 1 ada sebagian aktivitas belajar siswa belum seperti yang diharapkan oleh peneliti. Untuk itu dilakukan siklus 2. Data mengenai aktivitas belajar selama proses pembelajaran pada siklus kedua dapat dilihat pada tabel berikut ini:

Tabel 4.12 Rekapitulasi Frekuensi Aktivitas Belajar Siswa dari pertemuan I dan Pertemuan II

\begin{tabular}{|l|c|c|c|c|}
\hline \multirow{3}{*}{ No } & \multirow{3}{*}{ Aktivitas } & \multicolumn{3}{|c|}{ SIKLUS II } \\
\cline { 3 - 5 } & & Pertemuan & Pertemuan & Peningkatan \\
& & 1 & 2 & \\
\hline
\end{tabular}




\begin{tabular}{|c|c|c|c|c|c|c|c|}
\hline & & \multirow[t]{2}{*}{$\mathrm{F}$} & \multirow[t]{2}{*}{$\%$} & \multirow[t]{2}{*}{$\mathrm{f}$} & \multirow[t]{2}{*}{$\%$} & \multicolumn{2}{|c|}{$\begin{array}{c}\text { Pertemuan } 1 \mathrm{ke} \\
2\end{array}$} \\
\hline & & & & & & $F$ & $\%$ \\
\hline 1 & Bertanya & 29 & 80.55 & 32 & 88.88 & 3 & 7.5 \\
\hline 2 & $\begin{array}{l}\text { Mendengarka } \\
\mathrm{n} \text { diskusi }\end{array}$ & 32 & 88.88 & 35 & 97.22 & 3 & 7.5 \\
\hline 3 & $\begin{array}{l}\text { Memberi } \\
\text { tanggapan }\end{array}$ & 23 & 63.88 & 32 & 88.88 & 9 & 22.5 \\
\hline 4 & $\begin{array}{l}\text { Membuat } \\
\text { laporan/ dan } \\
\text { menulis }\end{array}$ & 28 & 77.77 & 36 & 100 & 8 & 20 \\
\hline & Rata-rata & & 77.77 & & 93.75 & 5.75 & 14.375 \\
\hline
\end{tabular}

Sumber: pengolahan data primer, 2018

Dari tabel diatas memperlihatkan bahwa aktivitas bertanya dan memberikan tanggapan sudah mencapai $88.88 \%$ dengan peningkatannya sebanyak $7.5 \%$ dan $22.5 \%$ untuk siklus ke 2 dalam pertemuan ke dua ini. Sedangkan untuk aktivitas mendengarkan diskusi mencapai $97.22 \%$ dengan peningkatannya sebesar $7.5 \%$ serta peningkatan aktivitas belajar yang paling tinggi adalah membuat laporan yang sudah mencapai $100 \%$ atau peningkatannya sebesar $20 \%$. Artinya sudah seluruh siswa aktif di dalam proses pembelajaran PKn di dalam kelas dengan adanya metode pembelajaran Come's to Papa (Cooperation Management and Part to Part) ini. Untuk lebih jelasnya dapat dilihat pada grafik dibawah ini

Gambar 4.2 Grafik siklus II

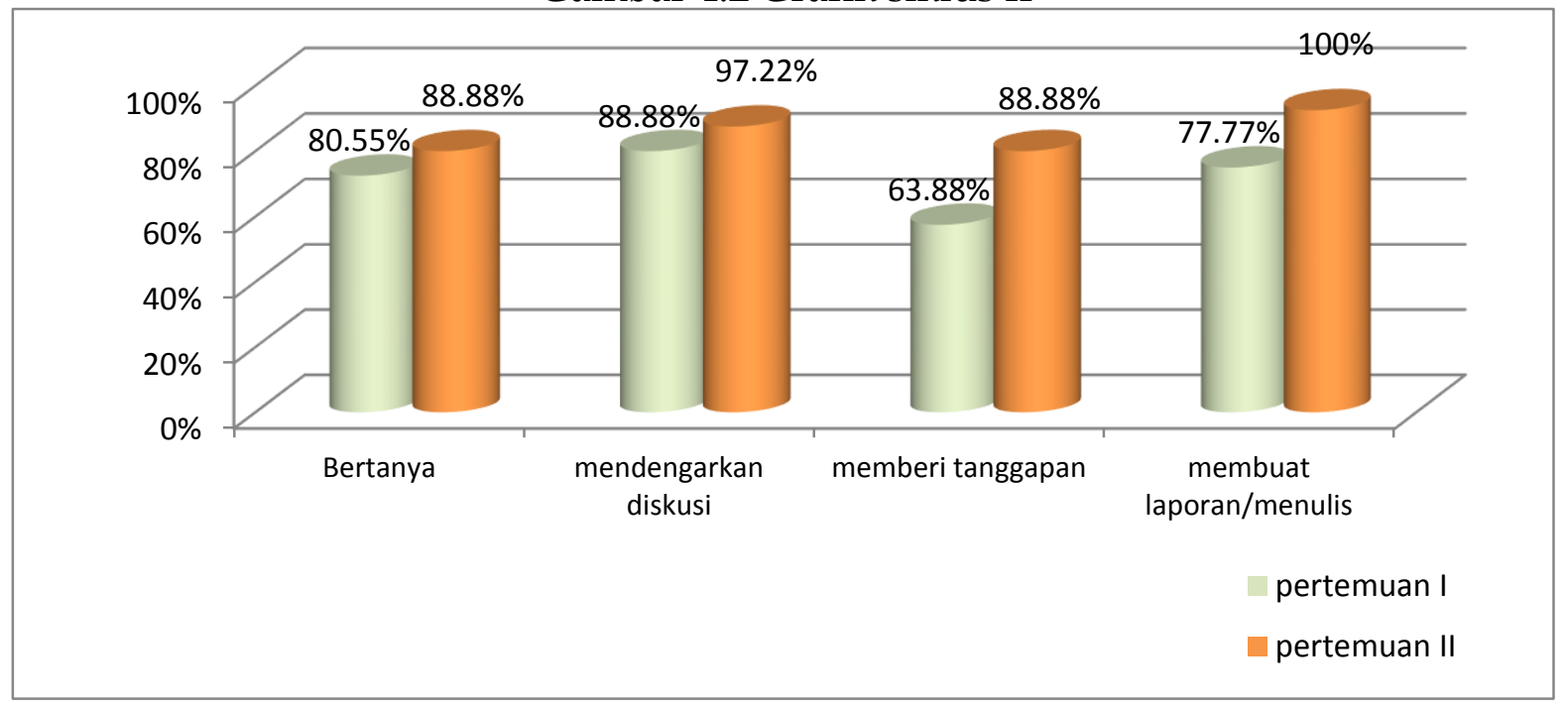

Berdasarkan tabel dan grafik diatas tergambar bahwa kegiatan pembelajaran siklus II dengan menggunakan model pembelajaran Come's to Papa (Cooperation Management and Part to Part) dapat mendorong dan meningkatkan aktivitas pada proses pembelajaran dari kegiatan Siklus I ke siklus II mencapai rata-rata $93.75 \%$ 
dari keempat aspek tersebut. Aktivitas belajara siswa yang telah mencapai $>80 \%$ sesuai dengan target yang telah ditetapkan.

Dari pengamatan peneliti dan observer pada pertemuan pertama sampai terakhir pada siklus 2 ini, pelaksanaan penelitian pada umumnya sudah berjalan seperti yang diharapkan, aktivitas siswa sudah semakin menunjukkan peningkatan,oleh karena itu peneliti mencukupkan penelitian pada siklus 2 ini.

\section{PEMBAHASAN}

\section{Siklus I}

Berdasarkan temuan dari penelitian pada siklus 1 dua kali pembelajaran dengan empat aktivitas yang diobservasi yaitu: bertanya, mendengarkan diskusi, memberi tanggapan, dan membuat laporan/mencatat, terlihat jelas bahwa masing-masing aktivitas mengalami peningkatan yang berbeda setiap pembelajaran. Aktivitas yang mengalami peningkatan adalah bertanya, mendengarkan diskusi, memberi tanggapan dan membuat laporan. Peningkatan aktivitas pada siklus 1 yang paling tinggi yaitu mendengarkan diskusi sebesar $83.33 \%$. Sedangkan yang paling rendah teradapat pada aktivitas memberi tanggapan yaitu sebesar $41.66 \%$.

Karena peningkatan aktivitas belum mencapai target yang diinginkan dan juga hasil refleksi dari siklus 1, maka dapat disimpulkan pada siklus 1 ini penerapan model pembelajaran Come's to Papa (Cooperation Management and Part to Part) ini belum optimal. Untuk itu, perlu adanya revisi dan perbaikan tentang cara pelaksanaan model pembelajaran Come's to Papa (Cooperation Management and Part to Part)dengan pemberiah hadiah untuk siswa yang aktif dalam proses pembelajaran.

\section{Siklus 2}

Pada Siklus kedua juga dilakukan dalam dua kali pembelajaran terlihat jelas adanya peningkatan aktivitas yang signifikan pada seluruh aktivitas. Peningkatan tinggi terjadi pada aktivitas membuat laporan/menulis, mendengarkan diskusi, dan memberi tanggapan dan aktiviats bertanya. Penerapan pada model pembelajaran Come's to Papa (Cooperation Management and Part to Part) sudah baik dan optimal bila dibandingkan dengan pelaksanaan pada siklus I setelah diperkuat anjuran kepada siswa untuk lebih meningkatkan kualiatas pada mendengarkan diskusi serta memberi tanggapan. Siswa lebih percaya diri untuk beraktivitas pada setiap pembelajaran berlangsung terutama pada saat guru menggunakan model pembelajaran Come's to Papa (Cooperation Management and Part to Part).

Menurut Sardiman (2005: 145) bahwa "guru hanya dapat merangsang dan memberikan dorongan serta reinfoecement untuk mendinamisasikan potensi sesuatu, menimbulkan swadaya (aktivitas) dan daya (kreativitas) sehingga akan terjadi dinamika di dalam proses belajar mengajar".

Berdasarkan hasil penelitian Siklus I dan siklus II, maka penelitian ini tidak dilanjutkan ke siklus berikutnya, karena hasil yang diperoleh pada siklus II 
telah memenuhi indikator keberhasilan yang telah ditetapkan. Dengan demikian penerapan model pembelajaran Come's to Papa (Cooperation Management and Part to Part)didalam proses belajar mengajar dapat meningkatkan aktivitas siswa dalam mata pelajaran PKn di kelas XI.IPA.1 SMAN 1 Kec. Lareh Sago Halaban.

\section{PENUTUP}

Berdasarkan Hasil Pelaksanaan Penelitian Tindakan Kelas Mengenai Penerapan Model Come's to Papa (Cooperation Management and Part to Part) pada siswa kelas XI.IPA 1 SMAN 1 Kec. Lareh Sago Halaban, dalam Mata Pelajaran PKn yang berlangsung selama 2 siklus Penelitian ini dapat disimpulkan:

1. Selama berlangsung PTK, Upaya Penerapan Model Come's to Papa (Cooperation Management and Part to Part) harus dikelola dengan baik.

2. Kegiatan Pembelajaran dengan Model Come's to Papa (Cooperation Management and Part to Part) yang dikelola dengan baik ternyata cukup efektif terhadap Peningkatan Aktivitas Belajar.

3. Hipotesis Tindakan yang menyatakan "Melalui Penerapan Model Come's to Papa (Cooperation Management and Part to Part) dapat meningkatkan aktifitas belajar PKn bagi siswa kelas XI.IPA.1 semester 1 Tahun Pelajaran 2018/2019 SMAN 1 Kec. Lareh Sago Halaban." Dapat Diterima.

\section{DAFTAR RUJUKAN}

Hamdani. 2011. Strategi Belajar Mengajar. Bandung: Pustaka Setia Hamdani. 2011.

http:// Panduan guru. Com/ Model-model- Pembelajaran /Pengertianya di Unduh tanggal 10 januari 2015

Nurhadi. 2002. Pendekatan Kontekstual. Malang :Universitas Negeri Malang.

Wardhani,Igak.2008. Penelitian Tindakan Kelas Universitas Terbuka jakarta. 